\title{
Fusion of complementary information of SAR and optical data for forest cover mapping using random forest algorithm
}

\author{
Naveen Veerabhadraswamy, Guddappa M. Devagiri* and Anil Kumar Khaple \\ University of Agricultural and Horticultural Sciences, Shivamogga College of Forestry, Ponnampet, Kodagu 571 216, India
}

We developed a methodological framework for accurate forest cover mapping of Shivamogga taluk, Karnataka, India using multi-sensor remote sensing data. For this, we used Sentinel-1 Synthetic Aperture Radar (SAR) and Sentinel-2 optical data. These datasets were fused using principal component analysis technique, and forest and non-forest areas were classified using a random forest (RF) algorithm. Backscatter analysis was performed to understand the variation in $\gamma^{0}$ values between forest and non-forest sample points. The average $\gamma^{0}$ values of forest were higher than the non-forest samples in $\mathrm{VH}$ and $\mathrm{VV}$ polarizations. The average $\gamma^{0}$ backscatter difference between forest and non-forest samples was $8.50 \mathrm{~dB}$ in $\mathrm{VH}$ and $5.64 \mathrm{~dB}$ in VV polarization. The highest classification accuracy of $92.25 \%$ was achieved with the multi-sensor fused data compared to the single-sensor SAR $(78.75 \%)$ and optical $(83.10 \%)$ data. This study demonstrates that RF classification of multi-sensor data fusion improves the classification accuracy by $13.50 \%$ and $9.15 \%$, compared to SAR and optical data.

Keywords: Forest cover, mapping, multi-sensor data fusion, principal component analysis, remote sensing, random forest algorithm.

FOREST ecosystems deliver a range of services and play a crucial role in the global carbon cycle and for regulating the biospheric climate. Loss of forest through deforestation, degradation, wildfires, etc. has deleterious effects on humans, biodiversity, carbon and water dynamics and other ecosystem services. In order to acquire reliable information for effective forest management and conservation, and regeneration of forests, critical information such as forest cover, disturbed areas, biomass or growing stock volume and stand canopy height is necessary. The first two categories are thematic in nature, and can be directly detected and mapped from remote sensing data. The latter categories require inference from remote sensing data-based models ${ }^{1-6}$.

In the recent past, geospatial technology has proved its potentiality in precise assessment, mapping and monitoring of forest resources at varying spatio-temporal scales.

*For correspondence. (e-mail: gdevagiri@gmail.com)
Although optical earth observation data have long been successfully used for forestry applications ${ }^{2,7-9}$, the acquisition of cloud-free imagery is still a challenge with the optical systems. Moreover, they are passive, sensitive to illumination characteristics of the targets and weather dependent. These constraints lead to limited data availability ${ }^{10,11}$, which seems particularly relevant in regular forest monitoring.

Microwave being active sensors have enabled to overcome the limitations of optical sensors in terms of capturing better spatial details, and can be used in all types of weather conditions. Due to these inherent advantages, microwave data have been extensively used for landuse/land-cover mapping and other applications ${ }^{3,12}$. Dual polarized (VV and VH) Synthetic Aperture Radar (SAR) dataset was used for urban area mapping in Turkey, and the overall accuracy of classification was enhanced to $93.28 \%$ from $73.85 \%$ of single polarization VV $(\mathrm{VH})^{13}$. Polarization information of $\mathrm{HH}, \mathrm{HV}$ and VV from L-band ALOS PALSAR satellite has been highly useful in differentiating forest types ${ }^{14}$. Masjedi et al. ${ }^{15}$ used dualpolarized SAR textural information to identify forest and non-forest areas. Earlier studies have demonstrated the potential of C- and L-band SAR backscatter and SAR textural information for forest and non-forest area mapping, indicating the importance of SAR data ${ }^{1,16-19}$. Like optical sensors, microwave sensors also have certain limitations, as they are sensitive to geometric or surface roughness, moisture content and dielectric properties of the objects ${ }^{20}$. Furthermore, radar imagery is non-sensitive to spectral information that makes it difficult in data analysis and interpretation. Since these limitations are non-overlapping, microwave and optical data offer complementary information. Fusion of these datasets helps in artificially generating an image that is rich in spatial as well as spectral information ${ }^{12,21}$.

Until recently, satellite data from a different region of the electromagnetic spectrum have been used on a singlemode approach at varying spatial resolutions for various forestry applications. The use of multi-sensor satellite data for the mapping of forest cover is limited ${ }^{5}$, particularly in the Indian region owing to the unavailability of quality data. Development of multi-sensor satellite systems capable of capturing information in different regions of 
the electromagnetic spectrum, e.g. European Space Agency's (ESA's) Sentinel constellation offers opensource microwave, optical/multispectral and other imageries with high spatial, spectral and temporal resolutions. Multi-sensor data fusion opens up many possibilities for a better understanding of earth surface features ${ }^{12,21,22}$ and improves the classification accuracy to a greater extent ${ }^{23-27}$.

Fusion of microwave and optical sensor data has been performed in applications such as land $\operatorname{cover}^{24,26,28}$ and urban area mapping ${ }^{29,30}$. Kasapoğlu et al. ${ }^{31}$ used fusion data from ALOS-PALSAR and Landsat 7 ETM+ to classify forest types and documented improved classification accuracy of $4 \%$ compared to TM image alone. Laurin et $a l .{ }^{32}$ used canopy elevation model combination with satellite data from ALOS PALSAR, RADARSAT-2 and SPOT to classify forest types in the Alps region and achieved 97.7\% accuracy. Similarly, using multitemporal, multi-sensor and multi-polarized SAR data, Hütt et $a l{ }^{33}$ achieved the highest classification accuracy.

Over the years, several satellite data fusion techniques have been developed. The ones commonly used are principal component analysis (PCA), intensity hue-saturation (IHS), Brovery transformation (BT), multiplicative fusion, Ehlers fusion, high-pass filters (HPF), etc. Singh and Gupta $^{23}$ compared three data-fusion techniques, namely BT, multiplicative fusion and PCA. The classification accuracy of BT was highest $(99.67 \%)$ compared to the other techniques (multiplicative fusion: $98.71 \%$, PCA: $98.63 \%$ and original image: $97.76 \%$ ). On the contrary, according to Estornell et al. ${ }^{34}, \mathrm{PCA}$ is one of the outstanding pixel-level data fusion techniques to derive important land-cover information. Kuplich et al. ${ }^{35}$ used PCA to fuse ERS-1 and TM data, and performed classification using maximum likelihood method.

A variety of machine-learning algorithms developed recently have helped in improving land-cover classification. The most widely used algorithms include decision tree, random forest (RF), artificial neural network and support vector machine. Among these, RF classifier has been used extensively due to its robustness and good classification results $^{36-38}$. In the present study, we have developed an appropriate methodology for Sentinel-1 SAR and Sentinel-2 optical data fusion based on PCA for forest-cover mapping with high accuracy using RF machine learning algorithm. The outcome of this study will be significant since future satellite missions will have integration of both SAR and optical sensors on-board.

\section{Materials and methods}

\section{Study area}

The study area comprises Shivamogga Taluk situated in the southern part of Shivamogga district, Karnataka,
India (Figure 1). Geo-coordinates of the test site lie between $13^{\circ} 43^{\prime} 39^{\prime \prime} \mathrm{N}-14^{\circ} 08^{\prime} 15^{\prime \prime} \mathrm{N}$ lat. and $75^{\circ} 15^{\prime} 55^{\prime \prime} \mathrm{E}-$ $75^{\circ} 44^{\prime} 12^{\prime \prime} \mathrm{E}$ long. with an average altitude of $570 \mathrm{~m}$ amsl and average annual rainfall of $850 \mathrm{~mm}$. April and May have the highest mean maximum temperature $\left(38^{\circ} \mathrm{C}\right)$, while December and January have the lowest mean minimum temperature $\left(12^{\circ} \mathrm{C}\right)$. However, during the study period (2019), average annual rainfall of $990 \mathrm{~mm}$ with mean maximum temperature of $35^{\circ} \mathrm{C}$ and mean minimum temperature of $18^{\circ} \mathrm{C}$ were recorded. The test site experiences tropical wet and dry summer climate comprising semi-evergreen, deciduous and scrub forest types with different density levels such as very dense $(>70 \%)$, moderately dense $(40-70 \%)$, open $(10-40 \%)$ and scrub forests $(<10 \%)^{39}$.

\section{Data inputs}

Satellite data: In this study, we used open source ESA's Sentinel-1 (S1) and Sentinel-2 (S2) satellite data. S1 provides dual-polarized $(\mathrm{VV}+\mathrm{VH}) \mathrm{C}$-band radar images at a spatial resolution of $5 \mathrm{~m} \times 20 \mathrm{~m}$, and the sensor operates at a central frequency of $5.405 \mathrm{GHz}$. Over the land S1 acquires images with interferometric wide (IW, $250 \mathrm{~km}$ ) swath mode. S2 provides multispectral optical data with 13 bands ranging from 443 to $2190 \mathrm{~nm}$ wavelength and a spatial resolution of $10-60 \mathrm{~m}$. Both $\mathrm{S} 1$ and S2 data were regularly available over the test site with an average temporal resolution of six days. Sentinel-1A (S1A) ground resolution detected (GRD) level-1 product consists of multi-view $(10 \mathrm{~m} \times 10 \mathrm{~m})$ and ground range projected images using ellipsoid model WGS84. Sentinel2A (S2A) level-1C top-of-atmospheric (TOF) reflectance

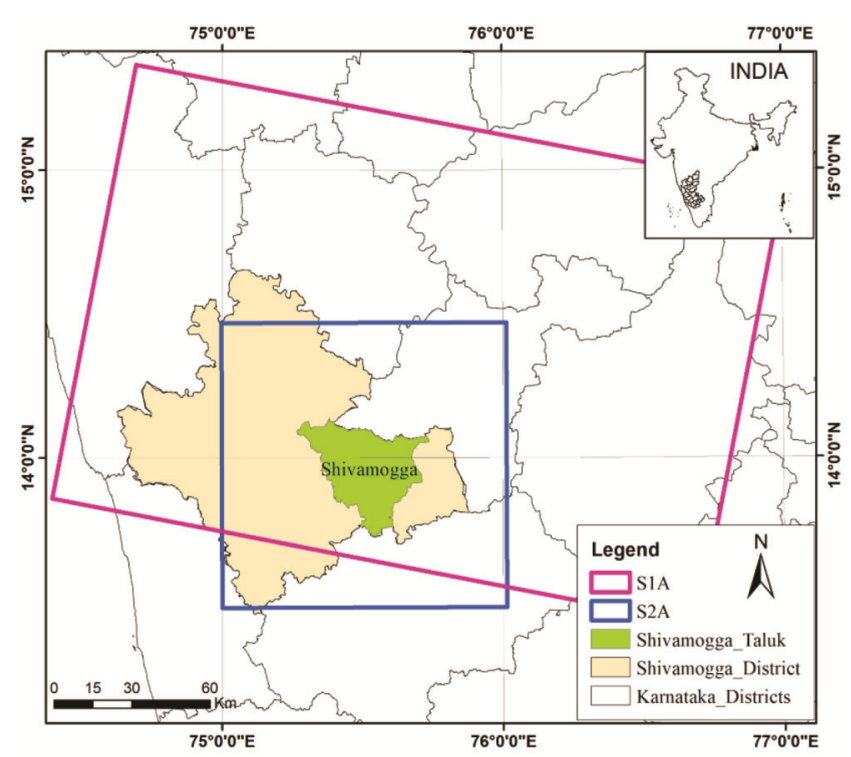

Figure 1. Location of the study area and coverage of Sentinel-1A and $-2 \mathrm{~A}$ satellite data.

CURRENT SCIENCE, VOL. 120, NO. 1, 10 JANUARY 2021 


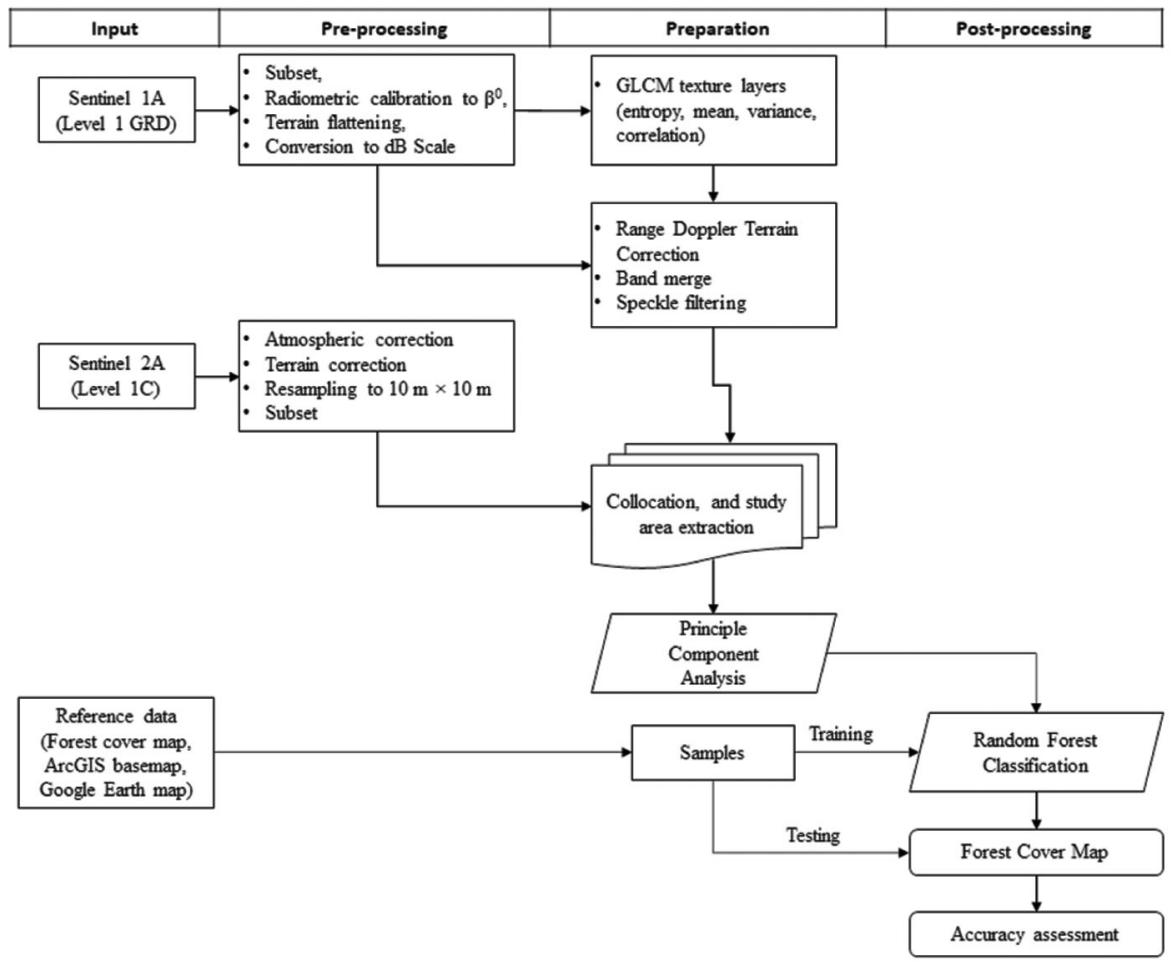

Figure 2. Block diagram showing workflow of the methodology.

data were downloaded from the ESA data hub (https:// scihub.copernicus.eu/). For this study, winter season (17 January 2019) datasets were used, since the C-band backscatter values for forest and agricultural crops were almost similar during summer, which could affect the classification accuracy ${ }^{19}$.

Reference data: Forest cover map of Shivamogga taluk developed by the Forest Survey of India (FSI) in 2019 was used as a reference map ${ }^{39}$. In addition, highresolution ArcGIS base maps and Google Earth Pro images were used to collect sample points for classifier training and validation of the result. FSI is a nodal agency involved in the assessment and monitoring of India's forest cover biennially. It has adopted the forest cover mapping methodology developed by National Remote Sensing Centre (NRSC) $)^{8,40}$, with some regular improvements to achieve high accuracy ${ }^{39}$. From the last few assessments, IRS Resourcesat-2 LISS III data have been used for mapping the country's forest cover with $23.5 \mathrm{~m}$ spatial resolution.

\section{Data pre-processing}

Figure 2 shows the methodology followed in this study. The satellite data were pre-processed using the Sentinel Application Platform (SNAP 6.0) toolbox. Pre-processing of S1A GRD data includes radiometric calibration to $\beta^{0}$ values, terrain flattening, range-Doppler terrain correction and linear to decibel scale conversion. First, the subset to the area of interest was extracted and calibrated to $\beta^{0}$. Subsequently, terrain flattening was performed to minimize the effect of topographical variations using the sensor vectors and SRTM 1-arc-second digital elevation model (DEM). This process coverts the $\beta^{0}$ values to $\gamma^{0}$ values $^{41}$. Geometric distortions of the SAR image were corrected using a range-Doppler algorithm and re-projected to UTM zone 43N/WGS84. The linear-scale backscatter image was stretched to the logarithmic scale by applying $10 * \log _{10}$.

Pre-processing of S2A data includes atmospheric correction, resampling and subsetting. The downloaded S2A level-1C TOA data were atmospheric and terrain corrected to reduce the solar illumination condition, mainly over the hilly terrain using ESA's SEN2COR toolbox, to obtain the S2A level-2A bottom-of-atmospheric reflectance image. In order to make uniform pixel size, S2A bands (except 1, 9 and 10) were resampled to $10 \times 10 \mathrm{~m}$ using the bilinear upscaling method, and the image was subset to the area of interest (as same as the S1A subset).

\section{Data preparation}

Grey level co-occurrence matrix: Spatial information retained in the form of textural patterns provides useful data for feature extraction ${ }^{42,43}$. Grey Level Co-occurrence 


\section{RESEARCH ARTICLES}

Matrix (GLCM) proposed by Haralick and Dinstein ${ }^{42}$ is widely used to extract second-order textural characteristics in a satellite image. GLCM is a method that quantifies the spatial relationship between adjacent pixels by measuring the likelihood of occurrence of two grey scales divided by a definite distance in a specified direction ${ }^{18,42}$. In order to furnish the classifier, the pre-processed S1A image was subjected to GLCM to derive second-order texture information such as entropy, mean, variance and correlation feature information for both the polarizations with a window size of $7 \times 7$ pixels. This results in eight textural layers, four from each polarization.

Principal component analysis: PCA is a pixel-level data fusion technique, a statistical tool used to transform the original image having correlated variables into a small set of uncorrelated variables using the co-variance matrix $^{21,44}$. The uncorrelated variables reveal most of the information, which helps in differentiating the land surface features easily. Besides, they identify the data redundancy, which helps reduce data dimensionality ${ }^{45}$. Finally, the pre-processed S1A (two bands) and S2A (10 bands) images, and the GLCM layers (eight bands) were subjected to PCA for data fusion.

\section{Post-processing}

Training and testing samples: Forest cover map of the study site, high-resolution ArcGIS basemap, S2A standard false colour composite and Google Earth Pro images were used for sample collection. Samples were manually digitized as single points associated with a single pixel

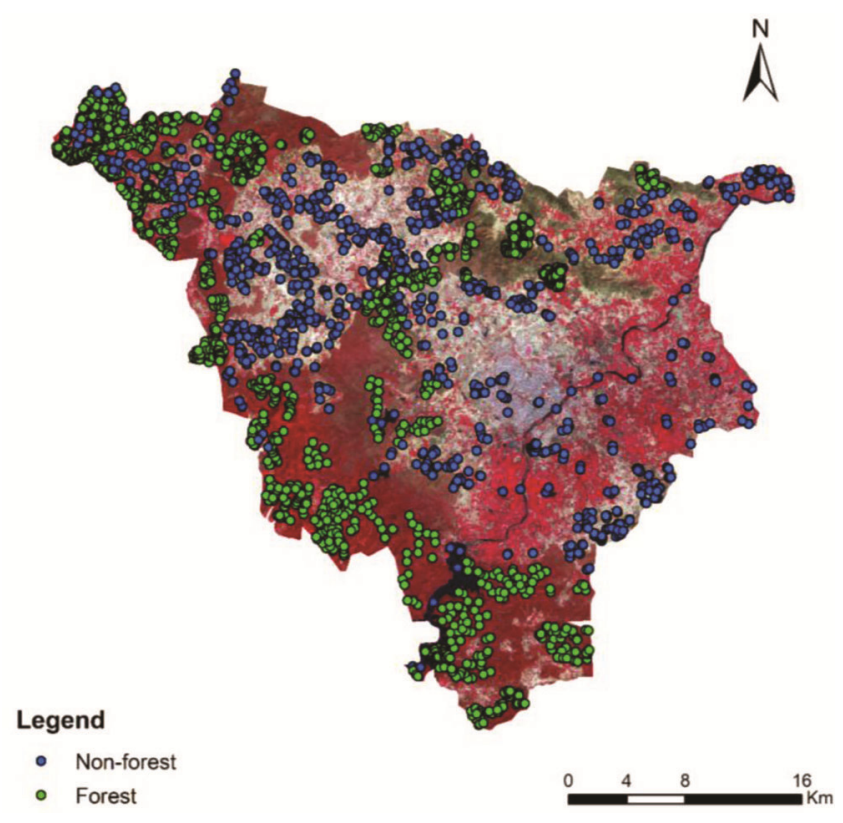

Figure 3. Spatial distribution of sample points in the study area. in an image using a visual interpretation technique. Two thousand spatially distributed sample points were collected randomly for each class (forest and non-forest) over the test site (Figure 3). Out of the total sample points, $50 \%$ was used to train the algorithm and the remaining $50 \%$ to validate the classified map.

Random forest classifier: RF classifier is a machine learning algorithm developed by Breiman ${ }^{46}$. It is a type of non-parametrized modelling tool that uses training samples in bootstrap and decision tree technique. It calculates dependent variables (e.g. forest cover, land cover) by generating many decision trees like forest using part of the given training samples and randomly selected variables (non-sampled pixels) for each step/tree ${ }^{47}$. The remaining part of the training samples called 'out of the bag' (OOB) was generated for each decision tree, used to authorize the training model by deriving the classification error. For each decision tree, the learning machine produces an OOB for accurate estimates. Variables with importance values exceeding 0.01 were selected for classification. The RF classifier displays high prediction accuracy and good tolerance to outliers and noise. The SNAP toolbox (version 6.0) was used for algorithm training and classification. Some of the parameters, such as the number of trees, were predefined for RF classification (in our case, it was set as 500), while other parameters (maximum features, minimum samples per split, maximum depth and bootstrap) were left as default. We performed the classification on SAR, optical and fused SAR and optical images.

Accuracy assessment: We validated the final forest cover map from the reserved sample points (testing samples), which were not used to train the classification algorithm. Accuracy statistics was summarized using producer accuracy, user accuracy, overall accuracy and kappa coefficient, in addition to error matrix or confusion matrix $^{48}$.
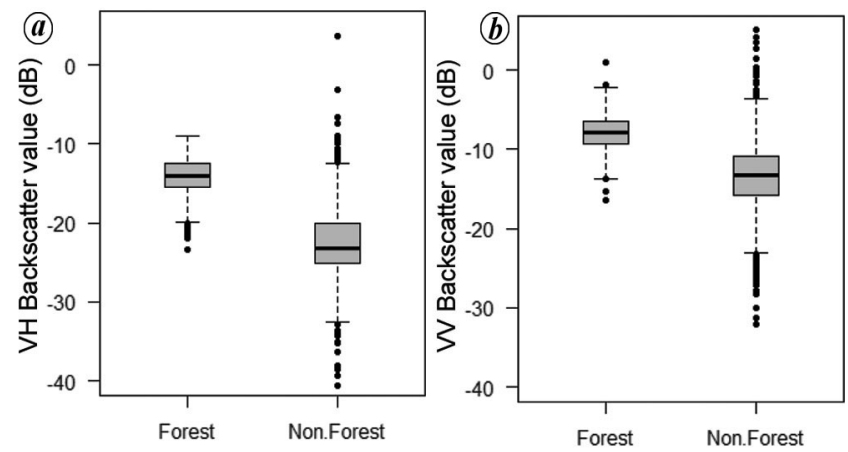

Figure 4. Distribution of $\gamma^{0}$ backscatter values of forest and nonforest training samples $(\boldsymbol{a})$ sample points in $\mathrm{VH}$ polarization and $(\boldsymbol{b})$ sample points in VV polarization. 
Table 1. Accuracy statistics of the classified images

\begin{tabular}{lccc}
\hline Accuracy & SAR alone & Optical alone & $\begin{array}{c}\text { Multi-sensor } \\
\text { (SAR + optical) }\end{array}$ \\
\hline User accuracy of forest & $76.94 \%$ & $80.03 \%$ & $93.33 \%$ \\
User accuracy of non-forest & $80.81 \%$ & $86.85 \%$ & $91.21 \%$ \\
Producer accuracy of forest & $82.10 \%$ & $88.20 \%$ & $91.00 \%$ \\
Producer accuracy of non-forest & $75.40 \%$ & $78.00 \%$ & $93.50 \%$ \\
Overall accuracy & $78.75 \%$ & $83.10 \%$ & $92.25 \%$ \\
Kappa coefficient & 0.57 & 0.66 & 0.85 \\
\hline
\end{tabular}

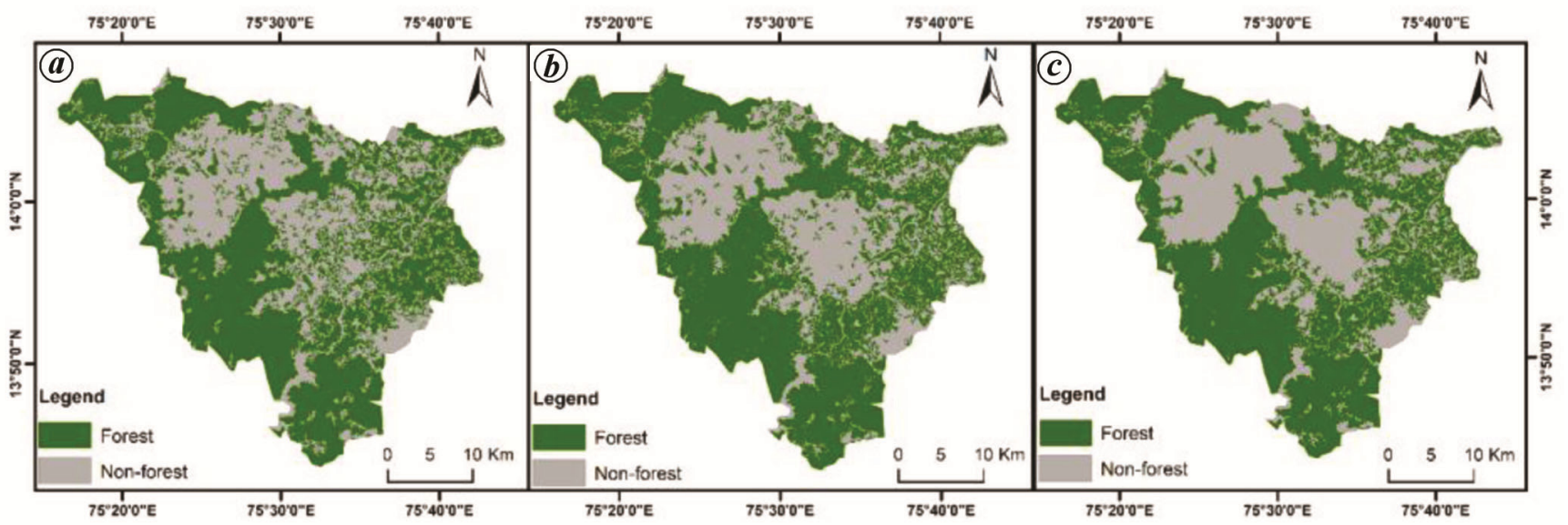

Figure 5. Forest cover map using (a) Sentinel-1A SAR data alone, (b) Sentinel-2A optical data alone, (c) Sentinel-1A and Sentinel-2A (SAR and optical) fused data.

\section{Results and discussion}

\section{Forest and non-forest backscatter analysis}

Figure 4 depicts the distribution of SAR backscatter $\gamma^{0}$ values in the test site for forest and non-forest samples. In both polarizations ( $\mathrm{VV}$ and $\mathrm{VH}$ ), backscatter values of forest samples showed little variation compared to that of non-forest samples, including samples from various landcover types such as built-up, water bodies, farmlands, etc. The average $\gamma^{0}$ values of forest were higher than the nonforest samples in both the polarizations, which may be attributed to differential backscattering properties coupled with different forest conditions. The average $\gamma^{0}$ values of forest and non-forest samples were $-14.13 \pm 0.07$ and $-22.62 \pm 0.15 \mathrm{~dB}$ respectively, in $\mathrm{VH}$ polarization. While, in VV polarization, it was $-7.87 \pm 0.07$ and $-13.51 \pm$ $0.16 \mathrm{~dB}$ respectively. However, the average difference between $\gamma^{0}$ values of forest and non-forest was highest with $8.50 \mathrm{~dB}$ in $\mathrm{VH}$ polarization compared to $5.64 \mathrm{~dB}$ in VV polarization.

Generally, the backscatter values are governed by sensor frequency, polarization, angle of incidence and other parameters specific to target features, mainly the structure and moisture conten $\mathrm{t}^{22}$. However, large difference in VH backscatter between forest and non-forest samples may be attributed to differential backscattering properties coupled with different target conditions. Mainly, the strong VH backscatter is the result of depolarization of SAR signals by forest canopies ${ }^{1,49}$. Furthermore, it may also be caused by forest detritus left after disturbance events like natural gap creation, illegal harvesting, etc. ${ }^{50}$. Devaney et al. ${ }^{1}$ reported strong HV backscatter values due to the depolarization of radar signals by the forest canopies in Sligo and Longford, Ireland.

\section{Classification accuracies}

Table 1 provides a summary of the accuracy statistics. We recorded the highest classification accuracy for fused multi-sensor (S1A and S2A) data compared to the single sensor SAR or optical (S1A or S2A) data (Figure 5). The overall classification accuracy of S1A data was $78.75 \%$ with the Kappa co-efficient of 0.57 , while S2A data outperformed the SAR data classification with $83.10 \%$ overall accuracy and Kappa co-efficient 0.66 respectively. The fused data achieved highest overall accuracy of $92.25 \%$ with the Kappa coefficient of 0.85 .

Even though backscatter analysis showed a significant difference in $\gamma^{0}$ values, it was difficult to differentiate forest and non-forest areas using S1A data alone. This is probably due to the misclassification of urban areas as forest and vice versa, since the central part of the test site 
is typically covered with the built-up or urban areas. Differentiating built-up area from the forest is crucial, since the backscattering mechanism of both are similar and result in almost similar backscatter values ${ }^{49,51}$. Whereas in the optical data, the confusion is mainly between forest, agricultural crops and grasslands pixels, which is due to the similar spectral properties ${ }^{17,52}$. However, SAR is known for its better capability in revealing structural information and dielectric properties of targets, while optical data are superior in distinguishing spectral signatures of the targets. Thus, the fusion of SAR and optical multi- sensor data is expected to improve the classification accuracy ${ }^{53}$.

The obtained results are in accordance with the earlier findings of land-cover mapping in different geographical regions integrating optical and SAR data from other satellites ${ }^{16,35,54,55}$. Yu et al. ${ }^{16}$ revealed that the classification accuracy of fused RADARSAT- 2 and SPOT- 5 data was better compared to that of using SPOT-5 data alone. Data integration reduces the confusion between misclassification of land uses and/or land covers ${ }^{30}$. Clerici et $a .^{24}$ and Steinhausen et al. $^{28}$ achieved better classification results with S1 and S2 fused image than the single sensor (S1 or S2) image.

\section{Conclusion}

SAR backscatter analysis showed a wide variation in $\gamma^{0}$ values between forest and non-forest samples. However, it was not possible to achieve higher level of classification accuracy with the SAR data alone. Similarly, though the accuracy of classification with optical data was slightly higher than SAR data, but we could not achieve the desired level. Therefore, the complementary information of SAR and optical data were fused to improve classification accuracy by reducing the misclassification between similar scattering and spectral pixels. An overall accuracy of $92.25 \%$ was achieved for multi-sensor (SAR and optical) fused data, while $78.75 \%$ and $83.10 \%$ was achieved by single sensor SAR and optical data respectively. The proposed forest-cover mapping approach has demonstrated the advantage of combining textural information of SAR and spectral information of optical data. Therefore, these results are the basis for future studies using SAR and optical time-series datasets for better understanding of tropical forest dynamics. These techniques may also be applicable to map trees outside the forest, which otherwise have been neglected in several forest inventories in the tropical regions.

1. Devaney, J., Barrett, B., Barrett, F., Redmond, J. and O'Halloran, J., Forest cover estimation in Ireland using radar remote sensing: a comparative analysis of forest cover assessment methodologies. PLoS ONE, 2015, 10(8), 1-27.

2. Reddy, C. S., Jha, C. S. and Dadhwal, V. K., Assessment and monitoring of long-term forest cover changes (1920-2013) in
Western Ghats biodiversity hotspot. J. Earth Syst. Sci., 2016, 125, 103-114.

3. Kellndorfer, J., Cartus, O., Bishop, J., Walker, W. and Holecz, F., Large scale mapping of forests and land cover with synthetic aperture radar data. In Land Applications of Radar Remote Sensing (eds Holecz, F. et al.), Intech Open, Rijeka, Croatia, 2016, pp. 59-94.

4. Reddy, C. S., Jha, C. S. and Dadhwal, V. K., Earth observations based conservation prioritization in Western Ghats, India. J. Geol. Soc. India, 2018, 92, 562-567.

5. Chakraborty, K., Sivasankar, T., Lone, J. M., Sarma, K. K. and Raju, P. L. N., Status and opportunities for forest resources management using geospatial technologies in northeast India. In Spatial Information Science for Natural Resource Management (eds Singh, S. K., Kanga, S. and Mishra, V. N.), IGI Global, Hershey, Pennsylvania, USA, 2020, pp. 206-224.

6. Mitchell, A. L., Rosenqvist, A. and Mora, B., Current remote sensing approaches to monitoring forest degradation in support of countries measurement, reporting and verification (MRV) systems for REDD ${ }^{+}$. Carbon Balance Manage., 2017, 12(9), 1-22.

7. Roy, P. S. and Joshi, P. K., Forest cover assessment in north-east India - the potential of temporal wide swath satellite sensor data (IRS-1C WiFS). Int. J. Remote Sensing, 2002, 23(22), 4881-4896.

8. Roy, P. S. et al., Development of decadal (1985-1995-2005) land use and land cover database for India. Remote Sensing, 2015, 7, 2401-2430.

9. Wang, Y. et al., Mapping tropical disturbed forests using multidecadal $30 \mathrm{~m}$ optical satellite imagery. Remote Sensing Environ., 2019, 221, 474-488.

10. Ju, J. and Roy, D. P., The availability of cloud-free Landsat $\mathrm{ETM}^{+}$ data over the conterminous United States and globally. Remote Sensing Environ., 2008, 112, 1196-1211.

11. Wagner, P. D., Kumar, S. and Schneider, K., An assessment of land use change impacts on the water resources of the Mula and Mutha rivers catchment upstream of Pune, India. Hydrol. Earth Syst. Sci., 2013, 17, 2233-2246.

12. Ghassemian, H., A review of remote sensing image fusion methods. Inf. Fusion, 2016, 32, 75-89.

13. Abdikan, S., Sanli, F. B., Ustuner, M. and Calò, F., Land cover mapping using Sentinel-1 SAR data. Int. Arch. Photogramm., Remote Sensing Spat. Inf. Sci., 2016, 757-761.

14. Touzi, R., Landry, R. and Charbonneau, F. J., Forest type discrimination using calibrated C-band polarimetric SAR data. Can. J. Remote Sensing, 2004, 30(3), 543-551.

15. Masjedi, A., Valadan Zoej, M. J. and Maghsoudi, Y., Classification of polarimetric SAR images based on modeling contextual information and using texture features. IEEE Trans. Geosci. Remote Sensing, 2016, 54(2), 932-943.

16. Yu, Y., Li, M. and Fu, Y., Forest type identification by random forest classification combined with SPOT and multitemporal SAR data. J. For. Res., 2017, 29, 1407-1414.

17. Navale, A. and Haldar, D., Evaluation of machine learning algorithms to Sentinel SAR data. Spat. Inf. Res., 2020, 28, 345355.

18. Ngo, K. D., Lechner, A. M. and Vu, T. T., Land cover mapping of the Mekong Delta to support natural resource management with multi-temporal Sentinel-1A synthetic aperture radar imagery. Remote Sensing Appl.: Soc. Environ., 2020, 17, 1-14.

19. Dostálová, A., Hollaus, M., Milenković, M. and Wagner, W., Forest area derivation from Sentinel-1 data. ISPRS Ann. Photogramm. Remote Sensing Spat. Inf. Sci., 2016, III(7), 227-233.

20. Moreira, A., Prats-Iraola, P., Younis, M., Krieger, G., Hajnsek, I. and Papathanassiou, K. P., A tutorial on synthetic aperture radar. IEEE Geosci. Remote Sensing Mag., 2013, 1(1), 6-43.

21. Kulkarni, S. C. and Rege, P. P., Pixel level fusion techniques for SAR and optical images: a review. Inf. Fusion, 2020, 59, 1329.

CURRENT SCIENCE, VOL. 120, NO. 1, 10 JANUARY 2021 
22. Schmitt, M. and Zhu, X. X., Data fusion and remote sensing: an ever-growing relationship. IEEE Geosci. Remote Sensing Mag., 2016, 4(4), 6-23.

23. Singh, R. and Gupta, R., Improvement of classification accuracy using image fusion techniques. In International Conference on Computational Intelligence and Applications, IEEE, Jeju, South Korea, 2016, pp. 36-40.

24. Clerici, N., Valbuena Calderón, C. A. and Posada, J. M., Fusion of Sentinel-1A and Sentinel-2A data for land cover mapping: a case study in the lower Magdalena region, Colombia. J. Maps, 2017, 13(2), 718-726.

25. Gaetano, R., Cozzolino, D., D'Amiano, L., Verdoliva, L. and Poggi, G., Fusion of SAR-optical data for land cover monitoring. In 2017 IEEE International Geoscience and Remote Sensing Symposium, Texas, USA, 2017, pp. 5470-5473.

26. Yuhendra, Y. E. and Na'am, J., Optical SAR fusion of Sentinel-2 images for mapping high resolution land cover. In 2018 International Conference on System Science and Engineering, New Taipei, Taiwan, 2018, pp. 1-4.

27. Fortin, J. A., Cardille, J. A. and Perez, E., Multi-sensor detection of forest-cover change across 45 years in Mato Grosso, Brazil. Remote Sensing Environ., 2020, 238, 1-14.

28. Steinhausen, M. J., Wagner, P. D., Narasimhan, B. and Waske, B., Combining Sentinel-1 and Sentinel-2 data for improved land use and land cover mapping of monsoon regions. Int. J. Appl. Earth Obs. Geoinf., 2018, 73, 595-604.

29. Wegner, J. D., Thiele, A. and Soergel, U., Fusion of optical and InSAR features for building recognition in urban areas. In Int. Arch. Photogramm. Remote Sensing (eds Stilla, U., Rottensteiner, F. and Paparoditis, N.), Paris, France, 2009, pp. 169-174.

30. Zhang, H., Zhang, Y. and Lin, H., Urban land cover mapping using random forest combined with optical and SAR data. In 2012 IEEE International Geoscience and Remote Sensing Symposium, Munich, Germany, 2012, pp. 6809-6812.

31. Kasapoğlu, G. N., Anfinsen, S. N. and Eltoft, T., Fusion of optical and multifrequency POLSAR data for forest classification. In 2012 IEEE International Geoscience and Remote Sensing Symposium, Munich, Germany, 2012, pp. 3355-3358.

32. Laurin, G. V. et al., Optical and SAR sensor synergies for forest and land cover mapping in a tropical site in West Africa. Int. J. Appl. Earth Obs. Geoinf., 2013, 21, 7-16.

33. Hütt, C., Koppe, W., Miao, Y. and Bareth, G., Best accuracy land use/land cover (LULC) classification to derive crop types using multitemporal, multisensor, and multi-polarization SAR satellite images. Remote Sensing, 2016, 8, 1-15.

34. Estornell, J., Martí-Gavliá, J. M., Sebastiá, M. T. and Mengual, J., Principal component analysis applied to remote sensing. Model. Sci. Educ. Learn., 2013, 6(7), 83-89.

35. Kuplich, T. M., Freitas, C. C. and Soares, J. V., The study of ERS1 SAR and Landsat TM synergism for land use classification. Int. J. Remote Sensing, 2000, 21, 2101-2111.

36. Belgiu, M. and Drăgu, L., Random forest in remote sensing: a review of applications and future directions. ISPRS J. Photogramm. Remote Sensing, 2016, 114, 24-31.

37. Gómez, C., White, J. C. and Wulder, M. A., Optical remotely sensed time series data for land cover classification: a review. ISPRS J. Photogramm. Remote Sensing, 2016, 116, 55-72.

38. Imangholiloo, M., Rasinmäki, J., Rauste, Y. and Holopainen, M., Utilizing Sentinel-1A radar images for large-area land cover mapping with machine-learning methods. Can. J. Remote Sensing, 2019, 45(2), 163-175.
39. ISFR, India State of Forest Report 2019, Forest Survey of India, Dehradun, Ministry of Environment, Forest and Climate Change, Government of India, 2019.

40. Rajashekar, G. et al., Remote sensing in forest mapping, monitoring and measurement. J. Gov. - Spl. Issue Environ., 2019, 18, 2754.

41. Small, D., Flattening gamma: radiometric terrain correction for SAR imagery. IEEE Trans. Geosci. Remote Sensing, 2011, 49(8), 3081-3093.

42. Haralick, R. M., Shanmugam, K. and Dinstein, I., Textural features for image classification. IEEE Trans. Syst. Man Cybern., 1973, SMC-3, 610-621.

43. Mishra, V. N., Prasad, R., Rai, P. K., Vishwakarma, A. K. and Arora, A., Performance evaluation of textural features in improving land use/land cover classification accuracy of heterogeneous landscape using multi-sensor remote sensing data. Earth Sci. Inform., 2019, 12, 71-86.

44. Zhang, J., Multi-source remote sensing data fusion: status and trends. Int. J. Image Data Fusion, 2010, 1(1), 5-24.

45. Braun, A. and Hochschild, V., Combined use of SAR and optical data for environmental assessments around refugee camps in semiarid landscapes. Int. Arch. Photogramm., Remote Sensing Spat. Inform. Sci., 2015, 777-782.

46. Breiman, L., Random forests. Mach. Learn., 2001, 45, 5-32.

47. Horning, N., Random forests: an algorithm for image classification and generation of continuous fields data sets. In International Conference on Geoinformatics for Spatial Infrastructure Development in Earth and Allied Sciences, Hanoi, Vietnam, 2010, pp. $1-6$.

48. Congalton, R. G. and Green, K., Assessing the Accuracy of Remotely Sensed Data: Principles and Practices, CRC Press/ Taylor \& Francis, Boca Raton, FL, USA, 2019, 3rd edn.

49. Anderson, F. et al., SAR Handbook: Comprehensive Methodologies for Forest Monitoring and Biomass Estimation, NASA, USA, 2019.

50. Whittle, M., Quegan, S., Uryu, Y., Stüewe, M. and Yulianto, K., Detection of tropical deforestation using ALOS-PALSAR: a Sumatran case study. Remote Sensing Environ., 2012, 124, 83-98.

51. Zou, B., Li, W., Xin, Y. and Zhang, L., Discrimination of forests and man-made targets in SAR images based on spectrum analysis. In Proceedings of SPIE 10988, Automatic Target Recognition XXIX, Baltimore, Maryland, USA, 2019, pp. 1-9.

52. Mercier, A. et al., Evaluation of Sentinel-1 and 2 time series for land cover classification of forest - agriculture Mosaics in temperate and tropical landscapes. Remote Sensing, 2019, 11, 1-20.

53. Pohl, C. and Van Genderen, J. L., Multisensor image fusion in remote sensing: concepts, methods and applications. Int. J. Remote Sensing, 1998, 19, 823-854.

54. Hong, G., Zhang, A., Zhou, F. and Brisco, B., Integration of optical and synthetic aperture radar (SAR) images to differentiate grassland and alfalfa in Prairie area. Int. J. Appl. Earth Obs. Geoinf., 2014, 28, 12-19.

55. Stefanski, J. et al., Mapping land management regimes in western Ukraine using optical and SAR data. Remote Sensing, 2014, 6, 5279-5305.

Received 8 June 2020; revised accepted 24 September 2020

doi: $10.18520 / \mathrm{cs} / \mathrm{v} 120 / \mathrm{i} 1 / 193-199$ 